\title{
Faktor-Faktor Penentu Kualitas Audit Serta Pengaruh Kualitas Audit \\ Terhadap Kepuasan Auditee Pada Pemerintah Daerah
}

by

\author{
Sarah Raharjo ${ }^{(1)}$ \\ Luh Putu Mahyuni (2) \\ Badan Pemeriksa Keuangan Republik Indonesia ${ }^{(1)}$ \\ Universitas Pendidikan Nasional ${ }^{(2)}$ \\ raden.joe@gmail.com ${ }^{(1)}$ \\ lpmahyuni@gmail.com ${ }^{(2)}$
}

\begin{abstract}
The purpose of the study is to investigate the influence of compliance, independence, professional care, commitment, and skeptical attitude towards audit quality and to empirically test the influence of audit quality on auditee satisfaction.

The object of the study was local government of Bali province. As many as 150 questionnaires were distributed, 115 were returned and filled. Data analyzed using Partial Least Square-Structural Equation Modelling (PLS-SEM).

The study finds that only proffesional care and skeptical attitude significantly influence audit quality. This study also provides empirical evidence of the influence of audit quality on auditee satisfaction.
\end{abstract}

Keywords: Compliance, Independence, Professional Care, Commitment, Skeptical Attitude, Audit Quality, Auditee Satisfaction 


\begin{abstract}
ABSTRAK
Penelitian ini bertujuan untuk mengetahui pengaruh compliance, independence, professional care, commitment, skeptical attitude terhadap audit quality dan mengetahui pengaruh audit quality terhadap auditee satisfaction.

Studi dilakukan pada instansi Pemerintah Daerah Provinsi Bali. Pengumpulan data menggunakan kuesioner. Dari 150 buah kuesioner yang disebarkan, sebanyak 115 buah kuesioner kembali dan terisi lengkap. Data dianalisis dengan menggunakan Partial Least Square-Structural Equation Modelling (PLS-SEM).

Hasil pengujian menunjukkan bahwa dari lima faktor penentu kualitas audit, hanya professional care dan skeptical attitude saja yang berpengaruh signifikan terhadap audit quality, sementara tiga faktor lainnya (compliance, independence dan commitment) tidak berpengaruh signifikan terhadap audit quality. Penelitian ini juga membuktikan secara empiris adanya pengaruh signifikan antara audit quality dengan auditee satisfaction.

Kata Kunci: Compliance, Independence, Professional Care, Commitment, Skeptical Attitude, Audit Quality, Auditee Satisfaction
\end{abstract}




\section{PENDAHULUAN}

Badjuri dan Trihapsari (2004) mengungkapkan bahwa "akuntabilitas dan transparansi pengelolaan keuangan pemerintah pusat maupun daerah merupakan tujuan penting reformasi akuntansi dan administrasi sektor publik". Selanjutnya Badjuri dan Trihapsari (2004) mengatakan bahwa akuntabilitas dan transparansi tersebut dimaksudkan untuk memastikan bahwa pengelolaan keuangan pemerintah yang dilakukan aparatur pemerintah berjalan dengan baik. Hal tersebut seiring dengan tuntutan masyarakat agar organisasi sektor publik meningkatkan kualitas, profesionalisme dan akuntabilitas publik dalam menjalankan aktivitas pengelolaan keuangan pemerintah pusat/daerah. Pengelolaan keuangan pemerintah yang baik harus didukung audit sektor publik yang berkualitas, karena jika audit quality sektor publik rendah, kemungkinan memberikan kelonggaran terhadap lembaga pemerintah melakukan penyimpangan penggunaan anggaran. Selain itu juga mengakibatkan risiko tuntutan hukum (legitimasi) terhadap aparatur pemerintah yang melaksanakannya.

Audit quality yang baik akan memberikan konsekuensi bagi auditee. Salah satu bentuk konsekuensi tersebut adalah auditee satisfaction. Philip Kotler (1994) dalam Widagdo (2002) mendefinisikan auditee satisfaction sebagai tingkat perasaan seseorang setelah membandingkan kinerja atau hasil yang dirasakan dengan harapannya.

LKPP dan LKPD adalah pertanggungjawaban pemerintah atas pelaksanaan anggaran belanja negara dan daerah sebagaimana diatur dalam paket undang-undang keuangan negara. Paket undang-undang yang dimaksud meliputi Undang-Undang Nomor 17 Tahun 2003 tentang Keuangan Negara, Undang-Undang Nomor 1 Tahun 2004 tentang Perbendaharaan Negara, dan Undang-Undang Nomor 15 Tahun 2004 tentang Pemeriksaan Pengelolaan dan Tanggung Jawab Keuangan Negara. Berdasarkan paket undang-undang ditetapkan berbagai ketentuan baru sekaligus penyempurnaan dan perubahan mendasar dalam pengelolaan dan pertanggungjawaban keuangan negara /daerah.

Tujuan dikeluarkannya paket undang-undang tersebut, untuk mendorong agar pengelolaan keuangan negara/daerah lebih accountable dan kemudian semakin diperlukannya peningkatan kinerja audit quality pemerintah. Audit quality pemerintah, dalam hal ini yaitu audit quality yang dilakukan Badan Pemeriksa Keuangan (BPK), sebagai eksternal auditor dari pemerintahan.

Sebagian besar studi yang pernah dilakukan dalam rangka mengevaluasi kualitas audit, selalu membuat kesimpulan dari sudut pandang auditor. Sutton (1993) mengatakan 
banyak pengguna laporan akuntan mengkritik kualitas pekerjaan akuntan. Oleh karena itu pada penelitian ini, yang menjadi obyek penelitian adalah pihak- pihak yang terlibat dalam pengelolaan keuangan daerah dan melakukan penyusunan laporan keuangan daerah, selaku entitas akuntansi yang dimintai pertanggungjawaban dan diperiksa oleh BPK. Selanjutnya, entitas tersebut merupakan pihak pengguna jasa audit/auditee dari BPK, yang kemudian memberikan penilaian terhadap kualitas audit dan kepuasan auditee dari kinerja auditor pemerintah atau BPK.

Sepengetahuan peneliti masih terbatasnya jumlah penelitian di Indonesia yang menilai audit quality pemerintahan, dengan melihat dari sisi auditee, dan juga belum ditemukannya penelitian yang menilai auditee satisfaction pemerintahan. Dari uraian tersebut, menarik untuk meneliti kembali faktor-faktor penentu kualitas audit persepsian di Pemerintah Daerah (Studi pada Pemerintah Provinsi Bali Tahun 2018).

\section{TINJAUAN PUSTAKA}

Pada penelitian ini dasar penggunaan teori atribusi, terfokus pada penilaian auditee terhadap faktor-faktor eksternal yaitu yang berasal dari orang yang diamati atau dinilai. Diasumsikan pada lingkungan audit, auditee sebagai pengguna jasa juga memberikan penilaian terhadap prilaku atau sikap yang diperlihatkan oleh auditor. Namun penilaian tersebut terkait dengan persepsi masing-masing auditee dan menghasilkan kesimpulan berupa audit quality dan auditee satisfaction terhadap kinerja dari auditor dalam pelaksanaan pemeriksaan atau audit.

Mulyadi (2002) menyatakan bahwa "pelaksanaan audit harus memperhatikan faktorfaktor berikut: 1) Dibutuhkan informasi yang dapat diukur dan sejumlah kriteria (standar) yang dapat digunakan sebagai panduan untuk mengevaluasi informasi tersebut, 2) Penetapan entitas ekonomi dan periode waktu yang diaudit harus jelas untuk menentukan lingkup tanggungjawab auditor, 3) Bahan bukti harus diperoleh dalam jumlah dan kualitas yang cukup untuk memenuhi tujuan audit, 4) Kemampuan auditor memahami kriteria yang digunakan serta sikap independen dalam mengumpulkan bahan bukti yang diperlukan untuk mendukung kesimpulan yang akan diambilnya”.

Penilaian dilakukan dengan melihat dari terpenuhinya beberapa atribut audit quality yaitu: experience, industry expertise, responsiveness, compliance, independence, professional care, commitment, executive involvement, conduct of audit field work, member characteristics, dan skeptical attitude yang akan berdampak terhadap audit quality dan auditee satisfaction (Carcello et al.,1992) 
De Angello (1981) mendefinisikan audit quality sebagai "pasar menilai kemungkinan bahwa auditor akan memberikan a) penemuan mengenai suatu pelanggaran dalam sistem akuntansi klien; dan b) adanya pelanggaran dalam pencatatannya". Pada public sector, GAO (1986) mendefinisikan audit quality yaitu pemenuhan terhadap standar profesional dan terhadap syarat-syarat sesuai perjanjian, yang harus dipertimbangkan. Pengertian lain yang digunakan berkaitan dengan studi mengenai audit quality adalah analisis terhadap kualitas yang ditinjau dari aturan yang dibuat oleh aparatur pemerintah.

Audit quality seharusnya memberi penjelasan juga mengenai faktor- faktor yang menentukan kepuasan klien. Tetapi ternyata studi mengambil kesimpulan, kualitas pelayanan atau audit quality dan kepuasan klien merupakan sesuatu yang berdiri sendiri (Cronin dan Taylor, 1994).

Robbins (2006) mengungkapkan bahwa "persepsi adalah proses yang digunakan individu mengelola dan menafsirkan kesan indera mereka dalam rangka memberikan makna kepada lingkungan mereka". Beberapa tinjauan mengenai definisi persepsi menyimpulkan bahwa persepsi setiap individu tentang suatu obyek atau peristiwa bergantung pada suatu kerangka ruang dan waktu yang berbeda. Perbedaan tersebut disebabkan oleh dua faktor yaitu faktor dalam diri seseorang (aspek kognitif) dan faktor dunia luar (aspek stimulus visual). Dapat disimpulkan bahwa persepsi akan mempengaruhi sikap yang akan menentukan perilaku yang merupakan cerminan dari persepsi yang dimiliki seseorang.

Definisi auditee satisfaction pada penelitian Behn et al. (1997) mengacu pada Hall dan Elliot (1993), yang menyatakan bahwa konstruk kualitas pelayanan sering dilihat memiliki hubungan erat dengan kepuasan konsumen atau klien.

Parasuraman (1985) dalam Glynn dan Barnes (1996) mengungkapkan bahwa "ada dua atribut utama yang mempengaruhi kualitas jasa yaitu expected service dan perceived service". Apabila jasa yang diterima atau dirasakan sudah sesuai dengan yang diharapkan maka kualitas jasa dipersepsikan baik dan memuaskan. Jika jasa yang diterima melampaui harapan pelanggan maka kualitas jasa dipersepsikan sebagai kualitas yang ideal. Sebaliknya jika kualitas jasa yang diperoleh lebih rendah maka kualitas jasa buruk. Dengan demikian, baik tidaknya kualitas jasa tergantung pada kemampuan penyedia jasa dalam memenuhi harapan pelanggannya secara konsisten.

Perbedaan sektor pemerintah dengan private sector terletak pada beberapa hal, termasuk sifat operasinya, akuntansinya, dan pelaporan keuangannya. Unit pemerintahan 
berbeda dari private sector/organisasi komersil, contohnya: ketiadaan motif mencari untung, kepemilikan kolektif dari para konstituen (rakyat adalah pemilik), yang tidak berbagi secara proporsional dalam penyediaan barang atau jasa bagi pemerintah (Samelson et al. 2006). Adanya proses politik yang mempengaruhi proses pengambilan keputusan (Freeman dan Shoulders. 2003).

Carcello et al. (1992) meringkas 12 atribut kualitas atribut dari 41 komposit atribut audit quality, dan menunjukkan bahwa karakteristik yang melekat pada tim audit lebih penting daripada karakteristik KAP. Pada studi ini Carcello merangking berdasarkan perbandingan persepsi dari auditors, preparers dan users untuk membentuk komponen audit quality. 12 atribut audit quality tersebut yaitu: experience, industry expertise, responsivenes, compliance, independence, professional care, ommitment, executive involvement, conduct of audit field work, involvement of audit committee, member characteristics, dan skeptical attitude.

Selanjutnya Samelson et al. (2006) menguji faktor-faktor penentu audit quality dan auditee satisfaction di pemerintahan lokal, dengan mengeluarkan variabel involvement of audit committee, karena jarang ditemukan pada pemerintahan lokal.

Penyusunan kerangka pemikiran teoritis hanya menggunakan 5 komposit dari 12 komposit atribut-atribut audit quality, sebagai berikut: compliance, independence, professional care, commitment dan skeptical attitude, dikarenakan 5 komposit tersebut dianggap yang paling relevan berkaitan dengan audit quality di pemerintahan daerah. Penjelasan ringkas mengenai 5 atribut audit quality disajikan pada tabel berikut. 
Tabel 1. Penjelasan Lima Atribut Audit Quality

\begin{tabular}{|l|l|}
\hline COMPLIANCE & $\begin{array}{l}\text { Tim audit melaksanakan pemeriksaan sesuai } \\
\text { standar umum audit }\end{array}$ \\
\hline INDEPENDENCE & $\begin{array}{l}\text { Tim audit yang menjaga independensi in } \\
\text { appearance dan in fact (dalam fakta dan } \\
\text { penampilan) }\end{array}$ \\
\hline PROFESSIONAL & $\begin{array}{l}\text { Tim audit selalu bersikap hati-hati dan } \\
\text { profesional dalam melakukan perikatan audit }\end{array}$ \\
\hline CORE & $\begin{array}{l}\text { Tim audit memiliki komitmen terhadap audit } \\
\text { quality }\end{array}$ \\
\hline $\begin{array}{l}\text { SKEPTICAL } \\
\text { TTTITUDE }\end{array}$ & \begin{tabular}{l} 
profesional dalam perikatan audit \\
\hline
\end{tabular}
\end{tabular}

Sumber: Samelson et al., (The Determinants of Perceived Audit Quality and Auditee Satisfaction in Local Government. 2006)

Faktor-faktor penentu audit quality belum tentu sama dengan faktor-faktor penentu kepuasan klien, maka sangatlah penting untuk menentukan atribut audit quality mana yang berhubungan dengan audit quality dan auditee satisfaction. Gambar model penelitiannya sebagai berikut:

\section{Gambar 1 \\ Model Penelitian}

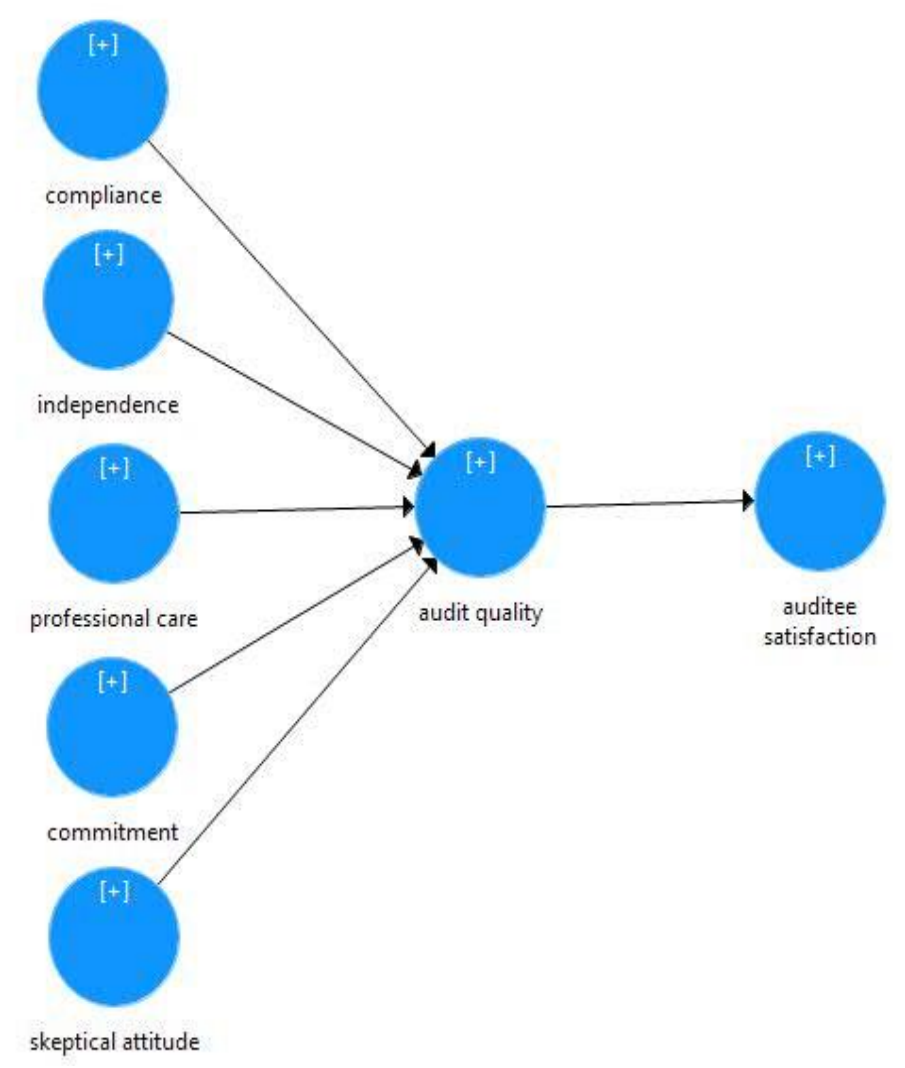




\section{Hipotesis Penelitian}

\section{Pengaruh Compliance terhadap Audit Quality}

Syarat utama menjadi seorang auditor adalah ia harus memiliki latar belakang pendidikan formal akuntansi dan auditing serta berpengalaman baik secara langsung maupun tidak langsung dalam bidang auditing (Tim, 1998). Elitzur dan Falk (1996) mengatakan, kredibilitas auditor tergantung pada: 1) kemungkinan auditor mendeteksi kesalahan yang material dan kesalahan penyajian, dan 2) kemungkinan auditor akan melaporkan apa yang ditemukannya.

Penelitian ini dimaksudkan untuk menguji kembali hubungan antara tim audit melaksanakan pemeriksaan sesuai standar umum audit/compliance dengan audit quality maka hipotesis pertama dalam penelitian ini adalah:

\section{H1 : Compliance berpengaruh terhadap audit quality}

\section{Pengaruh Independence terhadap Audit Quality}

Sikap independensi bermakna bahwa auditor tidak mudah dipengaruhi (Standar Profesi Akuntan Publik/SPAP 2001). Independensi menghasilkan obyektifitas, yang berpengaruh besar terhadap kualitas audit, sehingga auditor akan melaporkan apa yang ditemukannya selama proses pelaksanaan audit. Maka jika auditee mempersepsikan bahwa auditor telah memenuhi independensi sikap auditor, setelah mengamati sikap yang ditunjukkan oleh auditor selama melakukan pemeriksaan, kecenderung auditee akan menilai tim audit tersebut berkualitas dan menimbulkan kepuasan auditee.

Penelitian ini dimaksudkan untuk menguji kembali hubungan antara independensi tim audit/independence dengan audit quality, maka hipotesis kedua dalam penelitian ini adalah:

\section{$\mathrm{H}_{2}$ : Independence berpengaruh terhadap audit quality}

\section{Pengaruh Professional Care terhadap Audit Quality}

Temuan kesalahan pada laporan keuangan klien merupakan salah satu hal yang menunjukkan kualitas audit dan menunjukkan keahlian yang dimiliki oleh tim audit. Ahli diartikan sebagai ahli akuntansi dan audit (Standar Profesi Akuntan Publik/SPAP 2001) dan cermat menekankan pada pencarian tipe-tipe kesalahan yang mungkin ada melalui sikap hati-hati (Mautz dan Sharaf, 1961) 
Penelitian ini dimaksudkan untuk menguji kembali hubungan antara tim audit bersikap hati-hati dan professional dengan audit quality, maka hipotesis ketiga dalam penelitian ini adalah:

\section{H3 : Professional care berpengaruh terhadap audit quality}

\section{Pengaruh Commitment terhadap Audit Quality}

Araya et al. (1980) dalam Widagdo (2002) mendefinisikan komitmen sebagai berikut: (1) sebuah kepercayaan pada dan penerimaan terhadap tujuan-tujuan dari nilai-nilai organisasi dan atau profesi, (2) sebuah kemauan untuk menggunakan usaha yang sungguh-sungguh guna kepentingan organisasi dan atau profesi, (3) sebuah keinginan untuk memelihara keanggotaan dalam organisasi dan atau profesi.

Penelitian ini dimaksudkan untuk menguji kembali hubungan antara tim audit memiliki komitmen terhadap audit quality, maka hipotesis keempat dalam penelitian ini adalah:

\section{H4 : Commitment berpengaruh terhadap audit quality}

\section{Pengaruh Skeptical Attitude terhadap Audit Quality}

Audit atas laporan keuangan berdasarkan atas standar auditing yang ditetapkan Ikatan Akuntan Indonesia harus direncanakan dan dilaksanakan dengan sikap skeptisme profesional (Standar Profesi Akuntan Publik/SPAP 2001).

Maka jika auditee mempersepsikan bahwa auditor memiliki sikap skeptisme profesional, setelah mengamati sikap yang ditunjukkan oleh auditor selama melakukan pemeriksaan, kecenderung auditee akan menilai tim audit tersebut berkualitas dan menimbulkan kepuasan auditee.

Penelitian ini dimaksudkan untuk menguji kembali hubungan antara sikap skeptisme tim audit/skeptical attitude dengan audit quality, maka hipotesis kelima dalam penelitian ini adalah:

H5 : Skeptical attitude berpengaruh terhadap audit quality

\section{Pengaruh Audit Quality terhadap Auditee Satisfaction}

Dewiyanti (2000) menguji kembali atribut audit quality yang digunakan Bhen et al. (1997) dengan membentuk atribut tersebut menjadi suatu variabel audit quality 
kemudian mengujinya terhadap variabel kepuasan klien dan didapatkan hasil bahwa audit quality berpengaruh terhadap kepuasan klien.

Widagdo (2002) menguji pengaruh atribut-atribut audit quality terhadap kepuasan klien pada private sector. Menggunakan atribut-atribut audit quality yang dikembangkan oleh Carcello et al. (1992). Hasil penelitian menunjukkan atribut audit quality berpengaruh terhadap kepuasan klien.

Penelitian ini dimaksudkan untuk menguji kembali pengaruh variabel perceived audit quality terhadap auditee satisfaction, maka hipotesis keenam dalam penelitian ini adalah:

\section{H6 : Audit quality berpengaruh terhadap auditee satisfaction}

\section{METODE PENELITIAN}

Penelitian ini bertujuan untuk mengetahui pengaruh compliance, independence, professional care, commitment, skeptical attitude terhadap audit quality dan mengetahui pengaruh audit quality terhadap auditee satisfaction. Penelitian ini dilakukan dengan model pendekatan kuantitatif. Penelitian ini dilakukan pada auditee Pemerintah Daerah di wilayah Bali yang terlibat dalam pengelolaan keuangan daerah yang menjadi obyek pemeriksaan Badan Pemeriksa Keuangan Provinsi Bali, yang terdiri dari 8 Kabupaten, satu Kotamadya dan satu Provinsi Bali. Pengumpulan data menggunakan kuesioner. Kuesioner dibuat semenarik mungkin dan sesingkat mungkin namun tetap dapat mengumpulkan data-data yang ingin diteliti. Skala yang digunakan adalah skala 10 poin. Kuesioner yang disebarkan sebanyak 150 buah, 115 kembali dan 35 tidak kembali. Teknik pengambilan sampel dengan metode purposive sampling. Hubungan antara variabel bebas dan terikat pada penelitian ini dianalisis menggunakan Partial Least Square Structural Equation Modeling (PLS-SEM). Evaluasi model pengukuran dilakukan terlebih dahulu sebelum dilakukan evaluasi model struktural. 


\section{Evaluasi Model Pengukuran}

Model penelitian di bawah ini menunjukkan bahwa variabel konstruk Compliance (X1) diukur dengan 4 buah variabel indikator yaitu X1.1, X1.2, X1.3 dan X1.4. Variabel konstruk Independence (X2) diukur dengan 3 buah variabel indikator yaitu X2.1, X2.2 dan X2.3. Variabel konstruk Professional Care (X3) diukur dengan 3 buah variabel indikator yaitu X3.1, X3.2 dan X3.3. Variabel konstruk Commitment (X4) diukur dengan 3 buah variabel indikator yaitu X4.1, X4.2 dan X4.3. Variabel konstruk Skeptical Attitude (X5) diukur dengn 3 buah variabel indikator yaitu X5.1, X5.2 dan X5.3. Variabel konstruk Audit Quality (Y1) diukur dengan 1 buah variabel indikator yaitu Y1. Variabel konstruk Auditee Satisfaction (Y2) diukur dengan 1 buah variabel indikator yaitu Y2. Lihat pada gambar 2 berikut.

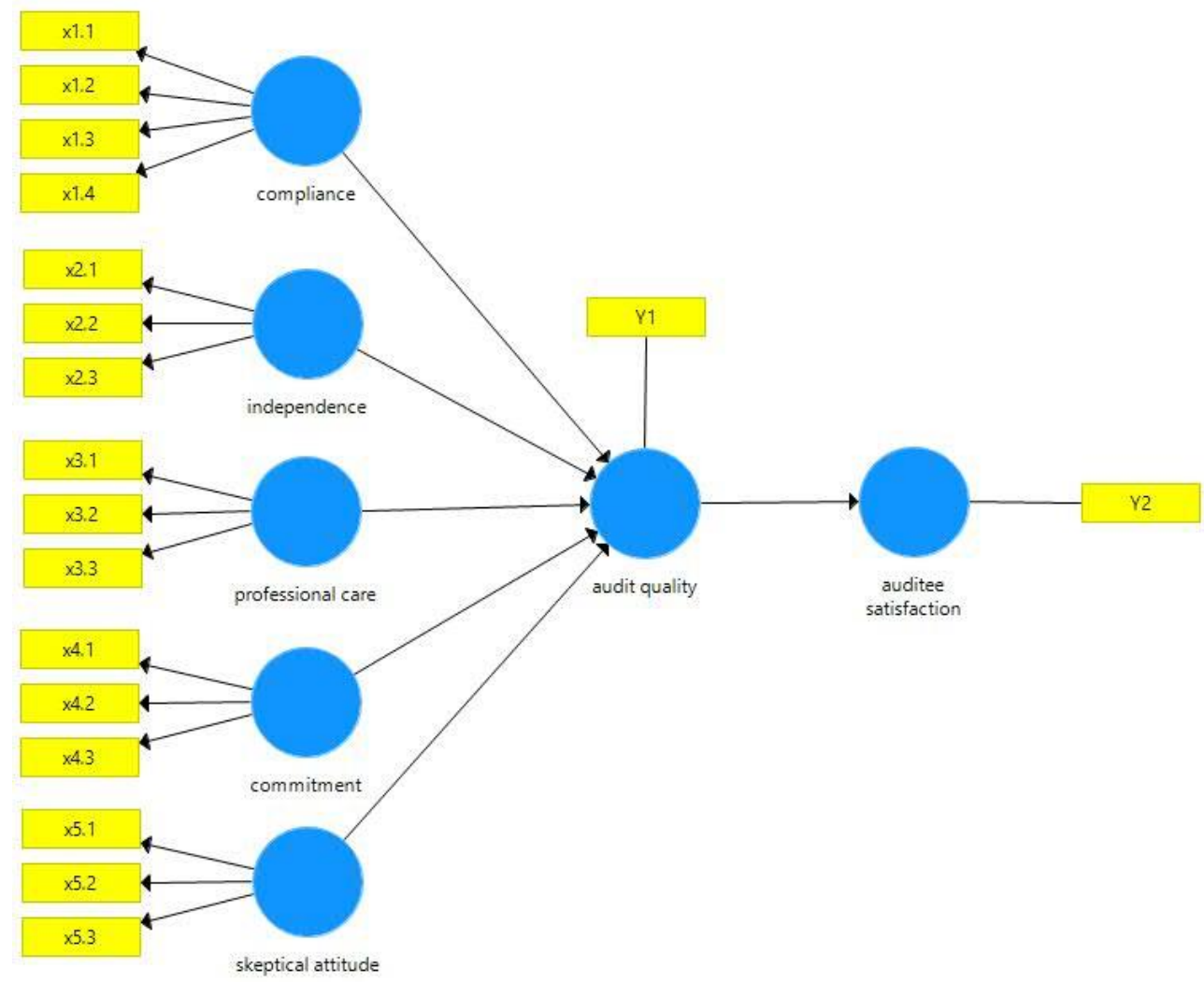

Untuk melakukan evaluasi reliabilitas dan validitas model pengukuran, pertama yang harus dilakukan adalah melihat hasil Convergent Validity. Ada dua hal yang harus diperhatikan yaitu nilai outer loading masing-masing variabel indikator terhadap variabel konstruknya harus $>$ 0,6 dan nilai AVE masing-masing variabel konstruk harus $>0.5$. Jika kedua hal ini terpenuhi maka dapat disimpulkan bahwa memenuhi Convergent Validity. Nilai composite reliability masing-masing variabel konstruk harus $>0.7$. Lihat pada gambar 3 berikut. 


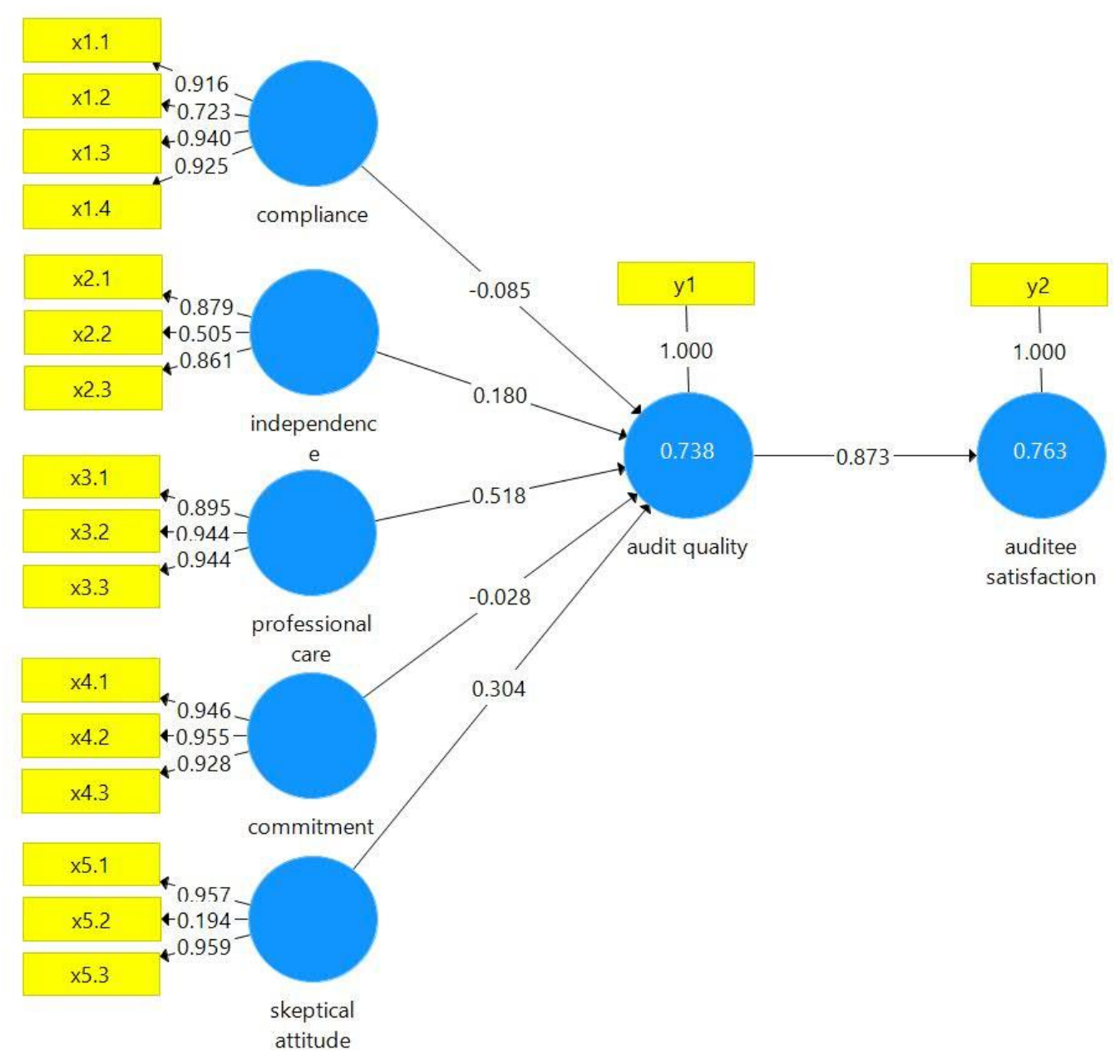

Tabel 7. Reliabilitas dan Validitas Model Pengukuran

\begin{tabular}{|c|c|c|c|c|c|}
\hline \multirow{2}{*}{$\begin{array}{l}\text { Variabel } \\
\text { Indikator }\end{array}$} & \multirow{2}{*}{$\begin{array}{l}\text { Variabel } \\
\text { Konstruk }\end{array}$} & \multicolumn{2}{|c|}{ Convergent Validity } & \multirow{2}{*}{$\begin{array}{c}\begin{array}{c}\text { Internal } \\
\text { Consistency } \\
\text { Reliability }\end{array} \\
\text { Composite } \\
\text { Reliability }\end{array}$} & \multirow{2}{*}{$\begin{array}{c}\begin{array}{c}\text { Discriminant } \\
\text { Validity }\end{array} \\
\text { Fornell- } \\
\text { Larcker } \\
\text { Criterion }\end{array}$} \\
\hline & & $\begin{array}{c}\text { Indicator } \\
\text { Outer } \\
\text { Loading }\end{array}$ & AVE & & \\
\hline $\mathbf{x 1 . 1}$ & \multirow{4}{*}{ Compliance } & 0.916 & \multirow{4}{*}{0.775} & \multirow{4}{*}{0.932} & \multirow{4}{*}{$\sqrt{ }$} \\
\hline $\mathbf{x 1 . 2}$ & & 0.723 & & & \\
\hline $\mathbf{x 1 . 3}$ & & 0.940 & & & \\
\hline $\mathbf{x 1 . 4}$ & & 0.925 & & & \\
\hline $\mathbf{x 2 . 1}$ & \multirow{3}{*}{ Independence } & 0.879 & \multirow{3}{*}{0.590} & \multirow{3}{*}{0.804} & \multirow{3}{*}{$\sqrt{ }$} \\
\hline $\mathbf{x 2 . 2}$ & & 0.505 & & & \\
\hline $\mathbf{x} 2.3$ & & 0.861 & & & \\
\hline $\mathbf{x 3 . 1}$ & \multirow{3}{*}{$\begin{array}{c}\text { Professional } \\
\text { Care }\end{array}$} & 0.895 & \multirow{3}{*}{0.861} & \multirow{3}{*}{0.949} & \multirow{3}{*}{$\sqrt{ }$} \\
\hline $\mathbf{x 3 . 2}$ & & 0.944 & & & \\
\hline $\mathbf{x 3 . 3}$ & & 0.944 & & & \\
\hline $\mathrm{x4.1}$ & Commitment & 0.946 & 0.889 & 0.960 & $\sqrt{ }$ \\
\hline
\end{tabular}


Tabel 7. Reliabilitas dan Validitas Model Pengukuran

\begin{tabular}{|c|c|c|c|c|c|}
\hline \multirow{2}{*}{$\begin{array}{c}\text { Variabel } \\
\text { Indikator }\end{array}$} & \multirow{4}{*}{$\begin{array}{c}\text { Variabel } \\
\text { Konstruk }\end{array}$} & \multicolumn{2}{|c|}{ Convergent Validity } & \multirow{4}{*}{$\begin{array}{c}\begin{array}{c}\text { Internal } \\
\text { Consistency } \\
\text { Reliability }\end{array} \\
\text { Composite } \\
\text { Reliability }\end{array}$} & \multirow{2}{*}{$\begin{array}{c}\begin{array}{c}\text { Discriminant } \\
\text { Validity }\end{array} \\
\text { Fornell- } \\
\text { Larcker } \\
\text { Criterion }\end{array}$} \\
\hline & & $\begin{array}{c}\text { Indicator } \\
\text { Outer } \\
\text { Loading }\end{array}$ & AVE & & \\
\hline $\mathrm{x4.2}$ & & 0.955 & & & \\
\hline $\mathrm{x} 4.3$ & & 0.928 & & & \\
\hline x5.1 & \multirow{3}{*}{$\begin{array}{l}\text { Skeptical } \\
\text { Attitude }\end{array}$} & 0.957 & \multirow{3}{*}{0.624} & \multirow{3}{*}{0.798} & \multirow{3}{*}{$\sqrt{ }$} \\
\hline$\times 5.2$ & & 0.194 & & & \\
\hline$\times 5.3$ & & 0.959 & & & \\
\hline y1 & Audit Quality & 1.000 & 1.000 & 1.000 & $\sqrt{ }$ \\
\hline y2 & $\begin{array}{c}\text { Auditee } \\
\text { Satisfaction }\end{array}$ & 1.000 & 1.000 & 1.000 & $\sqrt{ }$ \\
\hline
\end{tabular}

Pada variabel konstruk compliance (X1) terlihat bahwa masing-masing variabel indikator x1.1, x1.2, x1.3 dan x1.4 mempunyai nilai outer loading di atas 0,6 sehingga dapat dinyatakan bahwa semua variabel indikator tersebut memenuhi Convergent Validity terhadap variabel konstruk compliance (X1).

Pada variabel konstruk independence (X2) terlihat bahwa masing-masing variabel indikator x1.1 dan x1.3 mempunyai nilai outer loading di atas 0,6 sedangkan variabel indikator x1.2 mempunyai nilai outer loading di bawah 0,6 sehingga dapat dinyatakan bahwa semua variabel indikator tersebut belum memenuhi Convergent Validity terhadap variabel konstruk independence (X2) dan harus melakukan eliminasi terhadap variabel indikator $\mathrm{x} 1.2$

Pada variabel konstruk professional care (X3) terlihat bahwa masing-masing variabel indikator x3.1, x3.2 dan x3.3 mempunyai nilai outer loading di atas 0,6 sehingga dapat dinyatakan bahwa semua variabel indikator tersebut memenuhi Convergent Validity terhadap variabel konstruk professional care (X3).

Pada variabel konstruk commitment (X4) terlihat bahwa masing-masing variabel indikator x4.1, x4.2 dan x4.3 mempunyai nilai outer loading di atas 0,6 sehingga dapat dinyatakan bahwa semua variabel indikator tersebut memenuhi Convergent Validity terhadap variabel konstruk commitment (X4).

Pada variabel konstruk skeptical attitude (X5) terlihat bahwa masing-masing variabel indikator x5.1 dan x5.3 mempunyai nilai outer loading di atas 0,6 sedangkan variabel indikator x5.2 mempunyai nilai outer loading di bawah 0,6 sehingga dapat 
dinyatakan bahwa semua variabel indikator tersebut belum memenuhi Convergent Validity terhadap variabel konstruk skeptical attitude (X5) dan harus melakukan eliminasi terhadap variabel indikator x 5.2

Hasil tabel di atas menunjukkan bahwa nilai AVE dari masing-masing variabel konstruk sudah memenuhi syarat $>0,5$ dan nilai composite reliability pun sudah memenuhi syarat $>0,7$.

Iterasi Evaluasi Reliabilitas dan Validitas Model Pengukuran

Oleh karena pada proses uji reliabilitas dan validitas model pengukuran tahap pertama masih terdapat indikator yang tidak lolos uji, maka dilakukan kembali (iterasi) uji reliabilitas dan validitas model pengukuran dengan membuang indikator-indikator yang tidak lolos uji pada pengujian sebelumnya. Hasil iterasi evaluasi reliabilitas dan validitas model pengukuran disajikan pada Gambar 4 berikut:

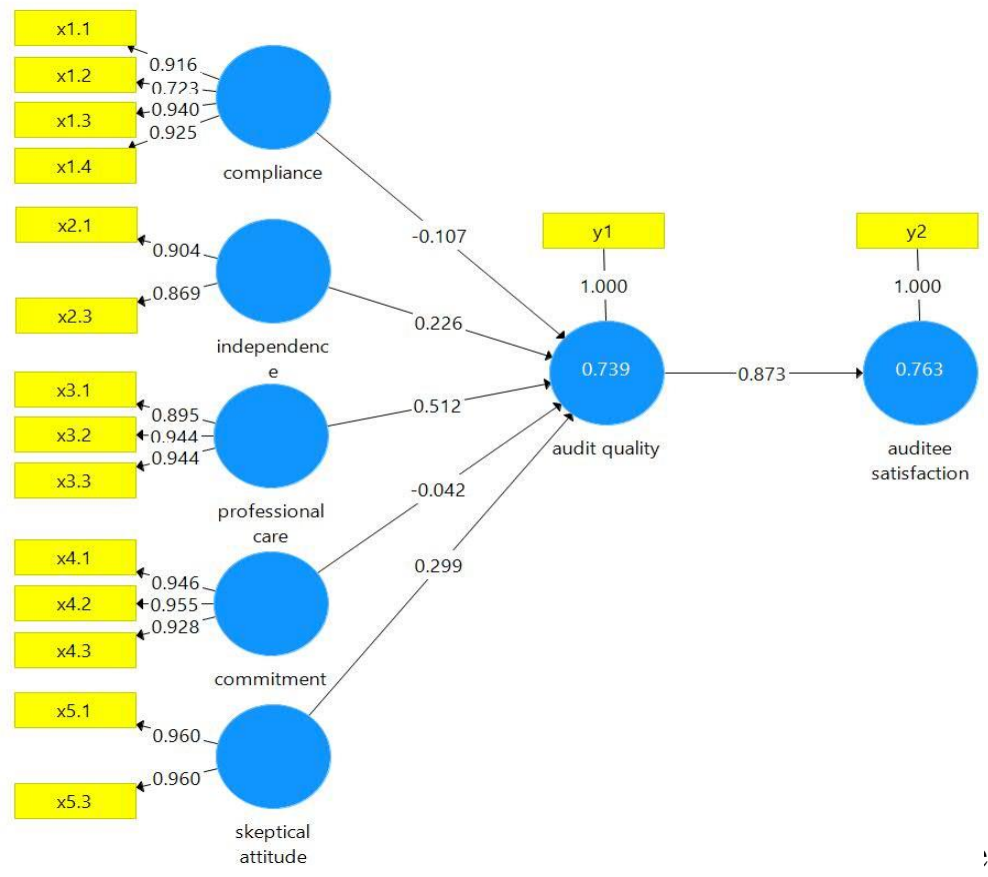

ngukuran

\begin{tabular}{|c|c|c|c|c|c|}
\hline \multirow{2}{*}{$\begin{array}{l}\text { Variabel } \\
\text { Indikator }\end{array}$} & \multirow{2}{*}{$\begin{array}{c}\text { Variabel } \\
\text { Konstruk }\end{array}$} & \multicolumn{2}{|c|}{ Convergent Validity } & \multirow{2}{*}{$\begin{array}{c}\begin{array}{c}\text { Internal } \\
\text { Consistency } \\
\text { Reliability }\end{array} \\
\text { Composite } \\
\text { Reliability }\end{array}$} & \multirow{2}{*}{$\begin{array}{c}\begin{array}{c}\text { Discriminant } \\
\text { Validity }\end{array} \\
\text { Fornell- } \\
\text { Larcker } \\
\text { Criterion }\end{array}$} \\
\hline & & $\begin{array}{c}\text { Indicator } \\
\text { Outer } \\
\text { Loading }\end{array}$ & AVE & & \\
\hline $\mathbf{x 1 . 1}$ & \multirow{4}{*}{ Compliance } & 0.916 & \multirow{4}{*}{0.775} & \multirow{4}{*}{0.932} & \multirow{4}{*}{$\sqrt{ }$} \\
\hline $\mathbf{x 1 . 2}$ & & 0.723 & & & \\
\hline $\mathbf{x 1 . 3}$ & & 0.940 & & & \\
\hline $\mathbf{x 1 . 4}$ & & 0.925 & & & \\
\hline $\mathbf{x} 2.1$ & Independence & 0.904 & 0.786 & 0.880 & $\sqrt{ }$ \\
\hline
\end{tabular}




\begin{tabular}{|c|c|c|c|c|c|}
\hline \multirow{2}{*}{$\begin{array}{l}\text { Variabel } \\
\text { Indikator }\end{array}$} & \multirow{3}{*}{$\begin{array}{l}\text { Variabel } \\
\text { Konstruk }\end{array}$} & \multicolumn{2}{|c|}{ Convergent Validity } & \multirow{3}{*}{\begin{tabular}{|c|}
$\begin{array}{c}\text { Internal } \\
\text { Consistency } \\
\text { Reliability }\end{array}$ \\
Composite \\
Reliability
\end{tabular}} & \multirow{2}{*}{$\begin{array}{c}\begin{array}{c}\text { Discriminant } \\
\text { Validity }\end{array} \\
\text { Fornell- } \\
\text { Larcker } \\
\text { Criterion } \\
\end{array}$} \\
\hline & & $\begin{array}{c}\text { Indicator } \\
\text { Outer } \\
\text { Loading }\end{array}$ & AVE & & \\
\hline $\mathrm{x} 2.3$ & & 0.869 & & & \\
\hline x3.1 & \multirow{3}{*}{$\begin{array}{c}\text { Professional } \\
\text { Care }\end{array}$} & 0.895 & \multirow{3}{*}{0.861} & \multirow{3}{*}{0.949} & \multirow{3}{*}{$\sqrt{ }$} \\
\hline $\mathbf{x 3 . 2}$ & & 0.944 & & & \\
\hline $\mathbf{x 3 . 3}$ & & 0.944 & & & \\
\hline $\mathrm{x4.1}$ & \multirow{3}{*}{ Commitment } & 0.946 & \multirow{3}{*}{0.889} & \multirow{3}{*}{0.960} & \multirow{3}{*}{$\sqrt{ }$} \\
\hline $\mathrm{x4.2}$ & & 0.955 & & & \\
\hline $\mathrm{x} 4.3$ & & 0.928 & & & \\
\hline $\mathbf{x 5 . 1}$ & \multirow{2}{*}{$\begin{array}{l}\text { Skeptical } \\
\text { Attitude }\end{array}$} & 0.960 & \multirow{2}{*}{0.921} & \multirow{2}{*}{0.959} & \multirow{2}{*}{$\sqrt{ }$} \\
\hline $\mathbf{x 5 . 3}$ & & 0.960 & & & \\
\hline y1 & Audit Quality & 1.000 & 1.000 & 1.000 & $\sqrt{ }$ \\
\hline y2 & $\begin{array}{c}\text { Auditee } \\
\text { Satisfaction }\end{array}$ & 1.000 & 1.000 & 1.000 & $\sqrt{ }$ \\
\hline
\end{tabular}

Pada variabel konstruk compliance (X1) terlihat bahwa masing-masing variabel indikator x1.1, x1.2, x1.3 dan x1.4 mempunyai nilai outer loading di atas 0,6 sehingga dapat dinyatakan bahwa semua variabel indikator tersebut memenuhi Convergent Validity terhadap variabel konstruk compliance (X1).

Pada variabel konstruk independence (X2) terlihat bahwa masing-masing variabel indikator x1.1, x1.2 dan x1.3 mempunyai nilai outer loading di atas 0,6 sehingga dapat dinyatakan bahwa semua variabel indikator tersebut memenuhi Convergent Validity terhadap variabel konstruk konstruk independence (X2).

Pada variabel konstruk professional care (X3) terlihat bahwa masing-masing variabel indikator x3.1, x3.2 dan x3.3 mempunyai nilai outer loading di atas 0,6 sehingga dapat dinyatakan bahwa semua variabel indikator tersebut memenuhi Convergent Validity terhadap variabel konstruk professional care (X3).

Pada variabel konstruk commitment (X4) terlihat bahwa masing-masing variabel indikator $\mathrm{x} 4.1, \mathrm{x} 4.2$ dan $\mathrm{x} 4.3$ mempunyai nilai outer loading di atas 0,6 sehingga dapat dinyatakan bahwa semua variabel indikator tersebut memenuhi Convergent Validity terhadap variabel konstruk commitment (X4).

Pada variabel konstruk skeptical attitude (X5) terlihat bahwa masing-masing variabel indikator x5.1, x5.2 dan x1.3 mempunyai nilai outer loading di atas 0,6 sehingga dapat dinyatakan bahwa semua variabel indikator tersebut memenuhi Convergent Validity terhadap variabel konstruk konstruk skeptical attitude (X5). 
Hasil tabel di atas menunjukkan bahwa nilai AVE dari masing-masing variabel konstruk sudah memenuhi syarat $>0,5$ dan nilai composite reliability pun sudah memenuhi syarat $>0,7$.

\section{Evaluasi Model Struktural}

Beberapa langkah yang dilakukan untuk melakukan penilaian model struktural yaitu korelasi antar variabel konstruk, koefisien determinasi (R-Square) dan bootstrapping t test.

1. Korelasi antar variabel konstruk

Tabel 9. Korelasi antar variabel konstruk

\begin{tabular}{|l|r|l|l|l|l|l|l|}
\hline Variable & $\begin{array}{l}\text { Audit } \\
\text { Quality }\end{array}$ & $\begin{array}{l}\text { Auditee } \\
\text { Satis }\end{array}$ & Commt & Compl & Indpc & $\begin{array}{l}\text { Profi } \\
\text { Care }\end{array}$ & $\begin{array}{l}\text { Skep } \\
\text { Att }\end{array}$ \\
\hline audit quality & 1.000 & & & & & & \\
\hline $\begin{array}{l}\text { auditee } \\
\text { satisfaction }\end{array}$ & 0.873 & 1.000 & & & & & \\
\hline commitment & 0.807 & 0.858 & 1.000 & & & & \\
\hline compliance & 0.775 & 0.811 & 0.882 & 1.000 & & & \\
\hline independence & 0.797 & 0.817 & 0.866 & 0.886 & 1.000 & & \\
\hline professional care & 0.840 & 0.867 & 0.934 & 0.898 & 0.865 & 1.000 & \\
\hline skeptical attitude & 0.823 & 0.855 & 0.901 & 0.869 & 0.870 & 0.896 & 1.000 \\
\hline
\end{tabular}

Tabel dSSemua variabel konstruk saling dikorelasikan, terlihat bahwa semua nilai korelasi di atas 0.4 , ini menunjukkan bahwa semua variabel konstruk berkorelasi positif dan memiliki kekuatan korelasi yang kuat antar variabel konstruk.

2. Koefisien Determinasi (R-Square)

Koefisien determinasi (R-Square) menunjukkan besarnya pengaruh variabel bebas terhadap variabel terikat.

Tabel 10. Koefisien Determinasi

\begin{tabular}{|l|r|r|}
\hline & $\begin{array}{c}\text { R } \\
\text { Square }\end{array}$ & $\begin{array}{c}\text { R } \\
\text { Square } \\
\text { Adjusted }\end{array}$ \\
\hline audit quality & 0.739 & 0.727 \\
\hline auditee satisfaction & 0.763 & 0.761 \\
\hline
\end{tabular}

Berdasarkan hasil tabel $R$ Square di atas dapat diketahui bahwa nilai $R$ Square Adjusted variabel konstruk Audit Quality adalah sebesar 0.727, ini berarti bahwa besarnya pengaruh kombinasi variabel konstruk Compliance, Independence, Professional Care, Commitment dan Skeptical Attitude terhadap Audit Quality adalah 
sebesar $72,7 \%$, sedangkan sisanya dipengaruhi oleh variabel konstruk lain yang tidak diteliti dalam model penelitian ini.

Kemudian dapat diketahui juga bahwa nilai $R$ Square Adjusted konstruk Auditee Satisfaction adalah sebesar 0.761, ini berarti bahwa besarnya pengaruh variabel konstruk Audit Quality terhadap Auditee Satisfaction adalah sebesar 76,1\%, sedangkan sisanya dipengaruhi oleh variabel konstruk lain yang tidak diteliti dalam model penelitian ini.

3. Bootsrapping $\mathrm{T}$ Test

Bootsrapping $\mathrm{T}$ Test dilakukan untuk mengetahui apakah suatu variabel bebas signifikan berpengaruh secara parsial terhadap variabel terikat.

Tabel 11. Bootsrapping T Test

\begin{tabular}{|l|r|r|r|r|r|}
\hline & $\begin{array}{c}\text { Original } \\
\text { Sample } \\
\text { (O) }\end{array}$ & $\begin{array}{c}\text { Sample } \\
\text { Mean } \\
\text { (M) }\end{array}$ & $\begin{array}{c}\text { Standard } \\
\text { Deviation } \\
\text { (STDEV) }\end{array}$ & $\begin{array}{c}\text { T Statistics } \\
\text { (|O/STDEV|) }\end{array}$ & $\begin{array}{c}\text { P } \\
\text { Values }\end{array}$ \\
\hline $\begin{array}{l}\text { audit quality -> auditee } \\
\text { satisfaction }\end{array}$ & 0.873 & 0.874 & 0.021 & 40.730 & 0.000 \\
\hline commitment -> audit quality & -0.042 & -0.053 & 0.159 & 0.262 & 0.793 \\
\hline compliance -> audit quality & -0.107 & -0.102 & 0.131 & 0.821 & 0.412 \\
\hline independence -> audit quality & 0.226 & 0.241 & 0.137 & 1.645 & 0.101 \\
\hline professional care -> audit quality & 0.512 & 0.505 & 0.168 & 3.051 & 0.002 \\
\hline skeptical attitude -> audit quality & 0.299 & 0.298 & 0.153 & 1.954 & 0.051 \\
\hline
\end{tabular}

Berdasarkan hasil tabel Bootstrapping T Test di atas dapat diketahui sebagai berikut.

a. Variabel konstruk Audit Quality adalah signifikan berpengaruh terhadap Auditee Satisfaction, yang ditunjukkan oleh nilai P-Value $=0.000<\alpha=0.05$. Sehingga dapat disimpulkan bahwa $\mathrm{H}_{6}$ audit quality berpengaruh terhadap auditee satisfaction terbukti.

b. Variabel konstruk Commitment diketahui tidak memiliki pengaruh signifikan terhadap variabel konstruk Audit Quality, ini ditunjukkan oleh nilai $P$-Value $=0.793$ $>\alpha=0.05$. Sehingga dapat disimpulkan bahwa $\mathrm{H}_{4}$ commitment berpengaruh terhadap audit quality tidak terbukti.

c. Variabel konstruk Compliance diketahui tidak memiliki pengaruh signifikan terhadap variabel konstruk Audit Quality, ini ditunjukkan oleh nilai $P$-Value $=0.412$ 
$>\alpha=0.05$. Sehingga dapat disimpulkan bahwa $\mathrm{H}_{1}$ compliance berpengaruh terhadap audit quality tidak terbukti.

d. Variabel konstruk Independence diketahui tidak memiliki pengaruh signifikan terhadap variabel konstruk Audit Quality, ini ditunjukkan oleh nilai $P$-Value $=0.101$ $>\alpha=0.05$. Sehingga dapat disimpulkan bahwa $\mathrm{H}_{2}$ independence berpengaruh terhadap audit quality tidak terbukti.

e. Variabel konstruk Professional Care diketahui signifikan berpengaruh terhadap variabel konstruk Audit Quality, ini ditunjukkan oleh nilai $P$-Value $=0.002$ $<\alpha=0.05$. Sehingga dapat disimpulkan bahwa $\mathrm{H}_{3}$ professional care berpengaruh terhadap audit quality terbukti.

f. Variabel konstruk Skeptical Attitude diketahui signifikan berpengaruh terhadap variabel konstruk Audit Quality, ini ditunjukkan oleh nilai $P$-Value $=0.051$ $\leq \alpha=0.05$. Sehingga dapat disimpulkan bahwa $\mathrm{H}_{5}$ skeptical attitude berpengaruh terhadap audit quality terbukti.

\section{HASIL DAN PEMBAHASAN}

\section{1. $\mathrm{H}_{1}$ : Compliance berpengaruh terhadap Audit Quality}

Hasil pengujian menunjukkan bahwa variabel konstruk Compliance menghasilkan nilai t hitung $=0.821$ dengan nilai $\mathrm{P}-$ Value $=0.412>\alpha=0.05$ menunjukkan bahwa tidak ditemukan pengaruh yang signifikan antara compliance dan audit quality.

Compliance adalah melaksanakan pemeriksaan sesuai standar umum audit. Compliance lebih banyak berkaitan dengan auditor dibandingkan dengan auditee. Sebagai auditee yang bukan seorang auditor kemungkinan besar digunakan auditee untuk mengetahui apakah suatu pemeriksaan ini sudah memenuhi standar umum audit atau belum.

“Carcello et al. (1992), Behn et al. (1997), Hanafi (2004) dan Semelson (2006) menyatakan bahwa compliance berpengaruh terhadap audit quality", ini bisa disebabkan karena responden penelitian adalah auditor yang merupakan orang yang paham apakah suatu pemeriksaan ini sudah memenuhi standar umum audit atau belum sedangkan dalam penelitian ini yang digunakan sebagai responden adalah bukan auditor. 


\section{2. $\mathrm{H}_{2}$ : Independence berpengaruh terhadap Audit Quality}

Hasil pengujian menunjukkan bahwa variabel konstruk Independence menghasilkan nilai $\mathrm{t}$ hitung $=1.645$ dengan nilai $\mathrm{P}-$ Value $=0.101>\alpha=0.05$ menunjukkan bahwa tidak ditemukan pengaruh yang signifikan antara independence dan audit quality.

Sikap independence bermakna auditor tidak mudah dipengaruhi sehingga hasil pemeriksaan bisa menunjukkan hasil yang obyektif. Sebagai auditee yang telah sering diaudit oleh auditor, auditee merasa bahwa audit belum bersifat obyektif karena masih ada kebijakan atau pemahaman antar auditor yang berbeda dalam menangani suatu kasus. Hal ini yang menyebabkan independence belum memiliki pengaruh terhadap audit quality dan didukung dengan penelitian yang dilakukan oleh Muh. Taufiq Effendy (2010) dan Ika Sukriah et al. (2009) yang menyatakan bahwa independence tidak berpengaruh terhadap audit quality.

\section{3. $\mathrm{H}_{3}$ : Professional care berpengaruh terhadap Audit Quality}

Hasil pengujian menunjukkan bahwa variabel konstruk Professional Care menghasilkan nilai $\mathrm{t}$ hitung $=3.051$ dengan nilai $\mathrm{P}$-Value $=0.002 \leq \alpha=0.05$ menunjukkan bahwa professional care signifikan memiliki pengaruh terhadap audit quality.

Professional care menunjukkan sikap kehati-hatian dan profesional dari seorang auditor dalam menentukan kesalahan. Dalam pandangan auditee, sikap kehati-hatian dan profesional dari seorang auditor dalam menentukan kesalahan sangat diapresiasi, sehingga tidak semua temuan menjadi sebuah kesalahan.

Sesuai dengan hasil penelitian dari Carcello et al. (1992), Behn et al. (1997), Hanafi (2004) dan Semelson (2006) menyatakan bahwa professional care berpengaruh terhadap audit quality.

\section{4. $\mathrm{H}_{4}$ : Commitment berpengaruh terhadap Audit Quality}

Hasil pengujian menunjukkan bahwa variabel konstruk commitment menghasilkan nilai t hitung $=0.272$ dengan nilai $\mathrm{P}-$ Value $=0.793>\alpha=0.05$ menunjukkan bahwa tidak ditemukan pengaruh yang signifikan antara commitment dan audit quality.

Commitment lebih terfokus pada nilai-nilai pribadi auditor, sehingga auditee tidak dapat menilai apakah komitmen seorang auditor sudah seperti seharusnya atau belum. Karena komitmen dari auditor tidak menjadi salah satu obyek pemeriksaan auditee. 


\section{H5 : Skeptical Attitude berpengaruh terhadap Audit Quality}

Hasil pengujian menunjukkan bahwa variabel konstruk Skeptical Attitude menghasilkan nilai $\mathrm{t}$ hitung $=1.954$ dengan nilai $\mathrm{P}$-Value $=0.051 \leq \alpha=0.05$ menunjukkan bahwa skeptical attitude signifikan memiliki pengaruh terhadap audit quality.

Skeptical attitude merupakan sikap kehati-hatian dan kewaspadaan terhadap bukti. Sikap auditor yang tidak langsung percaya terhadap apa yang disampaikan oleh auditee, pengumpulan data dan informasi dengan banyak bukti, dan pendeteksian kecurangan yang dilakukan oleh auditee akan dirasakan berdampak langsung oleh auditee sehingga dapat dinilai oleh auditee.

Hal ini sesuai dengan hasil penelitian dari Carcello et al. (1992), Behn et al. (1997), Hanafi (2004) dan Semelson (2006) menyatakan bahwa skeptical attitude berpengaruh terhadap audit quality

\section{H6 $_{6}$ : Audit Quality berpengaruh terhadap Auditee Satisfaction}

Hasil pengujian menunjukkan bahwa variabel konstruk Audit Quality menghasilkan nilai t hitung $=40.730$ dengan nilai $\mathrm{P}-$ Value $=0.000 \leq \alpha=0.05$ menunjukkan bahwa audit quality signifikan memiliki pengaruh terhadap auditee satisfaction.

Auditee satisfaction adalah tujuan akhir dari sebuah pemeriksaan. Auditee satisfaction dinilai berdasarkan audit quality yang langsung dirasakan oleh auditee. Sehingga jika audit quality itu baik maka auditee satisfaction juga akan baik.

Hal ini sesuai dengan hasil penelitian Carcello et al. (1992), Behn et al. (1997), Dewiyanti (2000) dan Widagdo (2002) menyatakan bahwa audit quality berpengaruh terhadap kepuasan klien

\section{KESIMPULAN DAN IMPLIKASI}

Penelitian dalam tesis ini bertujuan untuk mengetahui pengaruh atribut audit quality: compliance, independence, professional care, commitment, skeptical attitude terhadap audit quality dan mengetahui pengaruh audit quality terhadap auditee satisfaction. Berdasarkan hasil penelitian maka dapat diambil kesimpulan sebagai berikut:

1. Tidak ditemukan pengaruh yang signifikan antara compliance, independence, commitment dan audit quality.

2. Professional care dan skeptical attitude signifikan memiliki pengaruh terhadap audit 
quality, sehingga semakin baik tingkat professional care dan skeptical attitude yang dimiliki oleh auditor maka akan semakin baik audit quality yang dilakukannya.

3. Audit quality signifikan memiliki pengaruh terhadap auditee satisfaction sehingga semakin baik audit quality BPK Perwakilan Provinsi Bali maka persepsi auditee terhadap auditor semakin baik.

Adapun implikasi dari penelitian ini adalah sebagai berikut:

1. Implikasi Praktis

Penelitian ini berimplikasi pada BPK Provinsi Perwakilan Bali. Adanya pengaruh faktor Professional Care dan Skeptical Attitude terhadap kualitas audit yang dilaksanakan oleh BPK Perwakilan Provinsi Bali menunjukkan bahwa sikap kehatihatian dan professional dari seorang auditor dalam menentukan kesalahan atau menuliskan temuan telah tercapai dan sikap auditor yang tidak langsung percaya terhadap apa yang disampaikan auditee, pengumpulan data dan informasi dengan banyak bukti dan pendeteksian kecurangan yang dilakukan oleh auditee akan dirasakan berdampak langsung oleh auditee sehingga dapat dinilai oleh auditee dapat mempengaruhi Audit Quality.

Lebih jauh peneliti menganjurkan agar penentu kebijakan perlu terus menjaga dan meningkatkan kompetensi auditor melalui pemberian pelatihan-pelatihan serta kesempatan untuk mengikuti kursus-kursus atau peningkatan pendidikan profesi. Dan tidak hanya itu, penentu kebijakan juga tidak boleh melalaikan komitmen yang dimiliki auditor dalam menjalankan tugas audit serta memperhatikan dalam penyusunan tim agar memperhatikan auditor yang memiliki hubungan saudara dengan auditee supaya lebih bersifat obyektif.

\section{Implikasi Teoritis}

Sebagaimana telah dijelaskan sebelumnya, telah menunjukkan faktor-faktor penentu kualitas audit persepsian pada Pemerintah Daerah Provinsi Bali. Secara teoritis, hal ini mendorong arah riset selanjutnya untuk lebih spesifik meneliti hal-hal apa saja yang dapat mempengaruhi audit quality selain faktor-faktor yang telah diteliti dalam penelitian ini. 


\section{DAFTAR PUSTAKA}

Audit Quality, Journal of Accounting and Public Policy, 10: 245-266.

Badjuri, A., dan Elisa, T. (2004). Audit Kinerja pada Organisasi Sektor Publik Pemerintah. Basuki dan Krisna, Y., Mahardani. (2006). Pengaruh Tekanan Anggaran Waktu terhadap Perilaku Disfungsional Auditor dan Kualitas Audit pada Kantor Akuntan Publik di Surabaya, Jurnal Manajemen Akuntansi \& Sistem Informasi MAKSI UNDIP, 6 (2): 177-256.

Carcello, J. V., R. H. Hermanson., dan N. T. McGrath. (1992). Audit Quality.

Dewiyanti, S. (2000). Analisis Pengaruh Kualitas Audit dan Pergantian Auditor Terhadap Kepuasan Klien Kantor Akuntan Publik. Tesis Tidak dipublikasikan, Program Pasca Sarjana Magister Akuntansi Universitas Diponegoro.

Ferdinand, A. (2014). Structural Equation Modeling Dalam Penelitian Manajemen. Edisi Ke5. Semarang: Badan Penerbit Undip.

Ferdinand, A. (2014). Metode Penelitian Manajemen. Edisi Ke-5. Semarang: Badan Penerbit Undip.

Ghozali, I. (2006). Aplikasi Analisis Multivariate dengan Program SPSS. Semarang: Badan Penerbit Universitas Diponegoro.

Ghozali, I. (2006). Analisis Multivariate Lanjutan dengan Program SPSS. Semarang: Badan Penerbit Universitas Diponegoro.

Ghozali, I. (2008). Strultural equation modeling metode Alternatif dengan Partial Least Square. Semarang: Badan Penerbit Universitas Diponegoro.

Hanafi, I. (2004). Pengaruh Kualitas Audit dan Pergantian Auditor Terhadap Kepuasan Klien. Tesis Tidak dipublikasikan, Program Pasca Sarjana Magister Akuntansi Universitas Diponegoro.

http://www.bpk.go.id, diakses 30 Agustus 2018.

http://www.adeksi.or.id, Kamis 30 Agustus 2018, diakses 30 Agustus 2018.

Ikatan Akuntan Indonesia. (2001). Standar Profesional Akuntan Publik. Yogyakarta: STIE YKPN.

Ikhsan, A., dan M. Ishak. (2005). Akuntansi Keperilakuan. Jakarta: Badan Penerbit Salemba Empat.

Ishak, M. (2000). Analisis Faktor-Faktor Penentu Kualitas Audit Menurut Persepsi Klien, Tesis Tidak dipublikasikan, Program Pasca Sarjana Magister Akuntansi UGM.

JDI, DITAMA BINBANGKUM BPK-RI 2009. Standar Pemeriksaan Keuangan Negara, Jakarta. 
JDI, DITAMA BINBANGKUM BPK-RI 2017. Peraturan BPK Nomor 3 Tahun 2016 Tentang Kode Etik BPK dan Perturan BPK Nomor 4 Tahun 2016 Tentang Majelis Kehormatan Kode etik Badan Pemeriksa Keuangan, Jakarta.

Mardiasmo. (2006). Pewujudan Transparansi dan Akuntabilitas Publik Melalui Akuntansi Sektor Publik: Suatu Sarana Good Governance, Jurnal Akuntansi Pemerintah, 2 (1).

Saifuddin. (2004). Pengaruh Kompetensi dan Independensi Terhadap Opini Audit Going Concern (Studi Kuasieksperimen pada Auditor dan Mahasiswa). Tesis tidak dipublikasikan. Universitas Diponegoro, Semarang.

Samelson, D., Lowenshon, S., and Johnson, L. (2006). The Determinants of Perceived Audit Quality and Auditee Satisfaction in Local Government, Journal of Public Budgeting, Accounting, \& Financial Management, 18 (2).

Suharto, H. (2002). Quality Control PPA, IAI Mampu Menjamin Kualitas, Media Akuntansi. Edisi 24 / Maret / Tahun IX.

Sukariana, I.W., and Darma, G.S. (2015). Peran Audit Dalam Pengendalian Internal Serta Pengungkapan Kerugian Material Untuk Good Corporate Governance, Jurnal Manajemen \& Bisnis, 12 (2): 181-194.

Widagdo, R. (2002). Analisis Pengaruh Atribut-Atribut Kualitas Audit Terhadap Kepuasan Klien. Tesis Tidak dipublikasikan, Program Pasca Sarjana Magister Akuntansi Universitas Diponegoro.

Widiatmika, P.H., and Darma, G.S. (2018). Good Corporate Governance, Job Motivation, Organization Culture Which Impact Company Financial Performance, Jurnal Manajemen \& Bisnis, 15 (3): 82-99. 